Research Article

\title{
Topological Characteristics of Obstacles and Nonlinear Rheological Fluid Flow in Presence of Insulated Fins: A Fluid Force Reduction Study
}

\author{
Afraz Hussain Majeed $\left(\mathbb{D},{ }^{1}\right.$ Fahd Jarad $\mathbb{D}^{2,3}$ Rashid Mahmood ${ }^{2},{ }^{1}$ and Imran Saddique ${ }^{4}$ \\ ${ }^{1}$ Department of Mathematics, Air University, PAF Complex E-9, Islamabad 44000, Pakistan \\ ${ }^{2}$ Depart of Mathematics, Cankaya University, Etimesgut, Ankara, Turkey \\ ${ }^{3}$ Department of Medical Research, China Medical University Hospital, China Medical University, Taichung, Taiwan \\ ${ }^{4}$ Department of Mathematics, School of Science, University of Management and Technology, Lahore-54770, Pakistan
}

Correspondence should be addressed to Fahd Jarad; fahd@cankaya.edu.tr

Received 7 July 2021; Accepted 9 August 2021; Published 18 August 2021

Academic Editor: Shams -ul-Islam

Copyright (C) 2021 Afraz Hussain Majeed et al. This is an open access article distributed under the Creative Commons Attribution License, which permits unrestricted use, distribution, and reproduction in any medium, provided the original work is properly cited.

\begin{abstract}
In this work, a comprehensive study of fluid forces and thermal analysis of two-dimensional, laminar, and incompressible complex (power law, Bingham, and Herschel-Bulkley) fluid flow over a topological cross-sectional cylinder (square, hexagon, and circle) in channel have been computationally done by using finite element technique. The characteristics of nonlinear flow for varying ranges of power law index $(0.4 \leq n \leq 1.6)$, Bingham number $(0 \leq \mathrm{Bn} \leq 50)$, Prandtl number $(0.7 \leq \operatorname{Pr} \leq 10)$, Reynolds number $(10 \leq \operatorname{Re} \leq 50)$, and Grashof number $(1 \leq \mathrm{Gr} \leq 10)$ have been examined. Considerable evaluation for thermal flow field in the form of dimensionless velocity profile, isotherms, drag and lift coefficients, and average Nusselt number $\left(\mathrm{Nu}_{\text {avg }}\right)$ is done. Also, for a range of $\mathrm{Bn}$, the drag forces reduction is observed for circular and hexagonal obstacles in comparison with the square cylinder. At $\mathrm{Bn}=0$ corresponding to Newtonian fluid, maximum reduction in drag force is reported.
\end{abstract}

\section{Introduction}

Since the last several decades, heat transfer from a single cylinder (circular, square) has been widely considered, given its significance in various fields of engineering mathematical problems. The key research factors for the design, maintenance of electric cooling system, evaporators, heat exchangers, thermal plants and automobile radiators, etc., can be reported. Moreover, thermal flow by natural, forced, and mixed convection from solid body to fluid stream has been simulated by many researchers in a variety of configurations. Ditchfield et al. [1] experimentally examined the effects of thermal flow on viscoplastic fluid by implementing a proposed model. Shyam et al. [2] considered the influence of nonisothermal and nonlinear viscous fluid flow over the pair of circular heaters at large Grashof number. Computations were reported by varying gap between cylinders to elucidate its impact on thermal flow field. Laidoudi et al. $[3,4]$ analyzed the characteristics of mixed convection thermal flow of dual circular cylinders at low Reynolds number. They also computed fluid forces and average Nusselt number and observed high Nusselt number on second obstacle compared to the first one due to thermal buoyancy. Kefayati et al. [5] have numerically investigated the effects of double diffusion and entropy generation of viscous fluid flow over a cold cylinder in a duct by Lattice Boltzmann technique. In addition, an enhancement in heat transfer was noticed due to increase in the length of diameter of the cylinder. The buoyancy effects on thermal flow characteristics of confined circular cylinder submerged laminar Poiseuille fluid are studied by Laidoudi et al. [6]. Masoumi et al. [7] have examined the influence of nonisothermal viscoplastic fluid flow inside the circular duck and also imposed the Galerkins Weighted Residual (GWR) scheme of FEM computation 
with hybrid mesh. The influence of Richardson number on flow and heat transfer topologies of an obstacle at high Reynolds number are examined by Zafar and Alam [8]. Laidoudi et al. [9] considered the effects of the free convection fluid flow between two cylinders at high Reynolds number in a circular duct and also provided the correlation impacts of the average Nusselt number.

In order to design structures for non-Newtonian fluid exposed in polymer processing activities, reliable knowledge about fluid forces is often necessary, and in this regard, the flow and heat transfer in the free convection regime have been considerably studied in extensive research resources in recent years. Bharti et al. $[10,11]$ investigated the characteristics of steady, incompressible, non-Newtonian fluid flow over a confined cylinder at low Reynolds number $R e \leq 40$. They solved the model by using QUICK algorithm and finite volume scheme. Shyam et al. [12] numerically studied the influence of thermal flow of free convection over a constant heated block in a square duck and also reported the effects of average Nusselt number on Grashof and Prandtl number against power law index. Baranwal and Chhabra [13] considered an incompressible free convective thermal flow of power law fluid over a confined cylinder in square cavity. In addition, they examined the geometric effects of the cylinder on thermal flow fields. A. Pantokratoras [14] numerically reported the flow of power law fluid over a rotating cylinder solved by using finite volume scheme through commercial code FLUENT. Gangawane and Manikandan [15] have explored the thermal flow features over a hexagonal block with constant temperature, solved by using finite volume technique with QUICK discretization and SIMPLE algorithm. Asnaashari and Tohidi [16] investigated the effects of flow and heat transfer of power law fluid in an unconfined computational domain. Dhiman and Shyam [17] have examined the influence of Reynolds number on unsteady heat transfer over an equilateral triangular block and created grid by GAMBIT and solved it by using FLUENT.

Nirmalkar and Chhabra [18] studied the characteristics of Bingham fluid flow over a heated submerged cylinder using finite element computation. Patel and Chhabra [19] have extensively examined heat transfer, fluid forces, and yield stress results in steady flow regime. Mahmood et al. [20] have simulated a plastic fluid flow of square cavity by using the open-source software package FEATFLOW submerged in Papanastasiou regularization. Liu et al. [21] investigated the characteristics of Bingham fluid flow in deeply buried rock. Thakur et al. [22] have been considered a forced convective heat transport of a Bingham fluid over a rotating circular cylinder at low Reynolds number. Rem et al. [23] investigated the influence of unsteady Bingham fluid flow in a fractured channel.

The Herschel-Bulkley fluid model narrates the rheological influence of viscoplastic fluids which occurred in innumerable applications in industry. Theses viscous fluids are characterized by yield stress which requires a finite stress for flow. The relation between the shear stress and the shear rate is nonlinear. Since thermal flow is important in industrial applications with viscoplastic fluid flow like paint, cosmetic, and petroleum, many researchers have examined the characteristics of thermal flow in such viscoplastic fluid flow regimes [24-32].

Zdanski and Vaz [33] have implemented a secondorder finite difference scheme to simulate a flow problem of incompressible $3 \mathrm{D}$ viscous fluid flow in a channel. Abbasi et al. [34] have numerically analyzed the impacts of hydrodynamic forces over a cylinder-based Lattice Boltzmann Method (LBM) at low Reynolds number. Also, they compared their results with numerical and experimental data for single square cylinder case. Mahmood et al. [35] studied the non-Newtonian flow in a channel driven cavity by using $P_{2}-P_{1}$ element pair for finite element computation. Abbasi et al. [36] examined the characteristics of fluid forces over square cylinders at varying range of gap spacing, solved by LBM computation. Khan et al. [37] imposed least square FEM computation of viscous fluid flow over a semicylinder block via COMSOL solver. Tomio et al. [38] implemented a numerical methodology, secondorder finite difference scheme to solve a flow problem. Characterization of fluid forces of nonlinear material in a channel is based on FEM computation at low Reynolds number [39-41].

This manuscript is organized as follows. in Section 1 and Section 2, the introduction of the problem and the flow configuration and governing equations with constitutive relations are explained. Numerical scheme and grid convergence are described in Section 3. Also, the results are compared with literature for code validation. In Section 4, we explain in detail all the results and discussion of the article. Finally, conclusion is mentioned in Section 5.

\section{Flow Configuration and Governing Equations}

A cylinder (square, hexagon, and circle) of diameter $L_{D}=$ 0.1 in an incompressible viscous polymer solution in laminar, steady, 2D flow regime is revealed in Figure 1. The surface of cylinders is maintained at a uniform temperature $T_{h}$ and flow with average velocity $U_{\infty}$. The total length of given benchmark problem is $L_{\text {up }}+L_{\text {down }}$, where $L_{\text {up }}=0.2$ is the upstream length and downstream length is $L_{\text {down }}=2$ from the center of the cylinder and height of the channel is 0.41 , respectively. Moreover, the thermophysical properties of fluids are considered to be free from temperature. Also, we have neglected the effects of viscous dissipation from heat equation.

The geometrical configuration of the problem is shown in Figure 1.

Continuity, momentum, and energy are the governing equations of steady, nonisothermal, and viscous incompressible fluid flow across an infinitely long channel in presence of heated cylinder. Their nondimensional forms of these equations are written as follows:

$$
\nabla \cdot \mathbf{u}=0
$$

$$
\mathbf{u} . \nabla \mathbf{u}+\nabla p=\frac{1}{\operatorname{Re}} \nabla \cdot \boldsymbol{\tau}+\frac{G r}{\operatorname{Re}^{2}} \boldsymbol{\theta}
$$




$$
\text { u. } \nabla \boldsymbol{\theta}=\frac{1}{\operatorname{RePr}} \nabla^{2} \boldsymbol{\theta},
$$

where $\tau$ represents the category of the chosen fluid. Here we have used three models, namely, power law, Bingham, and Herschel-Bulkley fluid defined as follows.

(i) Power law model:

$$
\tau=m(\dot{\gamma})^{n} .
$$

(ii) Bingham model:

$$
\begin{cases}\dot{\gamma}=0, & \tau \leq \tau_{y}, \\ \tau=\left(\frac{\tau_{y}}{\dot{\gamma}}+\mu_{p}\right) \dot{\gamma}, & \tau>\tau_{y} .\end{cases}
$$

(iii) Herschel-Bulkley model:

$$
\left\{\begin{array}{l}
\tau=\tau_{y}+m \dot{\gamma}^{n}, \\
\eta=\frac{\tau_{y}}{\dot{\gamma}}+m \dot{\gamma}^{n-1}, \quad \tau>\tau_{y} .
\end{array}\right.
$$

The nondimensionalized equations (1)-(3) suggest that velocity, pressure, and temperature fields are dependent on dimensionless parameters, Reynolds number (Re), Grashof number (Gr), Prandtl number (Pr), and Bingham number $(\mathrm{Bn})$. These parameters are defined as

$$
\begin{aligned}
\text { Reynolds number } \operatorname{Re} & =\frac{U_{\infty} L_{D}}{v}, \\
\text { Grashof number } \mathrm{Gr} & =\frac{g \beta\left(T_{h}-T_{0}\right) L_{D}^{3}}{v^{2}}, \\
\text { Prandtl number } \operatorname{Pr} & =\frac{v}{\alpha}, \\
\text { Bingham number } \mathrm{Bn} & =\frac{\tau_{0} L_{D}}{\mu U_{\infty}},
\end{aligned}
$$

where symbols have been defined in nomenclature. To compute the solution of equations (1)-(3), the system must be subject to some boundary conditions. At the inlet of this domain, fluid enters with parabolic profile in $x$-direction. At the outlet, the Neumann conditions for all variables have been imposed. On the surface of channel and obstacles there is no-slip boundary condition. Furthermore, fins are insulated and obstacles are heated uniformly while other walls of channel remain cold.

Ultimately, computational results from the preceding governing equations in the form of primitive variables $(\mathbf{u}, p$, and $\theta$ ), together with the above boundary conditions of the domain are postprocessed to evaluate the derived quantities like drag coefficient, lift coefficient, and $\mathrm{Nu}_{\text {avg }}$, respectively.
The nondimensional net drag $\left(F_{d}\right)$ and lift $\left(F_{l}\right)$ forces act on the submerged cylinder in the flow and normal direction, while the drag and lift coefficient are

$$
\begin{gathered}
C_{D}=\frac{2 F_{d}}{\rho U_{\infty}^{2} L_{D}}, \\
C_{L}=\frac{2 F_{l}}{\rho U_{\infty}^{2} L_{D}} .
\end{gathered}
$$

Here the reference velocity is $U_{\infty}=(2 / 3) U_{\max }$, where $U_{\max }=0.3$ is the maximum velocity of given parabolic profile at the inlet. The local Nusselt $\left(N u_{\text {local }}\right)$ number on the surface of duct and fins is estimated by $\mathrm{Nu}_{\text {local }}=-\left(\partial \theta / \partial n_{s}\right)$. Such values have been more averaged over both surfaces (cylinder and fins) to obtain the average Nusselt $\left(\mathrm{Nu}_{\mathrm{avg}}\right)$ number given as

$$
\mathrm{Nu}_{\text {avg }}=\frac{1}{S} \int_{s} \mathrm{Nu}_{\mathrm{local}} \mathrm{d} S,
$$

where " $S$ " and " $n_{s}$ " are the surfaces of thermal region and normal direction of the surface; it is reasonable to postulate that the drag coefficient is function of Rewhereas the $\mathrm{Nu}_{\text {avg }}$ depends on the Pr. This work endeavors to exhibit and develop more efficient functional relationship for circular cylinder in future.

\section{Numerical Scheme and Grid Convergence}

Due to nonlinearity of the governing equations as well as of non-Newtonian fluids, having plastic viscosity applied to channel flow, the energy and momentum equations cannot be supported with analytical solutions, so we implemented numerical scheme finite element method (FEM) for computing the optimized solution with different shapes of cylinder. The underlying discrete nonlinear system of equations has been solved by Newton method and the linearized inner system is solved with a direct solver PARDISO. The PARDISO solver utilizes LU matrix factorization and reduces the number of iterations required for the desired level of convergence. This reduces the number of the iterations required. The Lagrangian system was used for the velocity discretization (second order) of elements and pressures and temperatures (linear) as is shown in Figure 2.

Grid independence study has been performed for the $C_{D}, C_{L}$, and $\mathrm{Nu}_{\text {avg }}$ for the different cylinders and corresponding results are given in Table 1-Table 3 for all the three shapes of cylinders at $\operatorname{Re}=20, \operatorname{Pr}=6.2, \mathrm{Bn}=0, n=1$, and $\mathrm{Gr}=10$. The benchmark results reveal the fact that results at levels 7 and 8 are in close agreement so to save computational cost, and we performed the rest of the simulation at level 7.

Finally, the current code has also been validated against the Schaefer and Turek [42] in Table 4 by setting the temperature on circular cylinder as zero. 


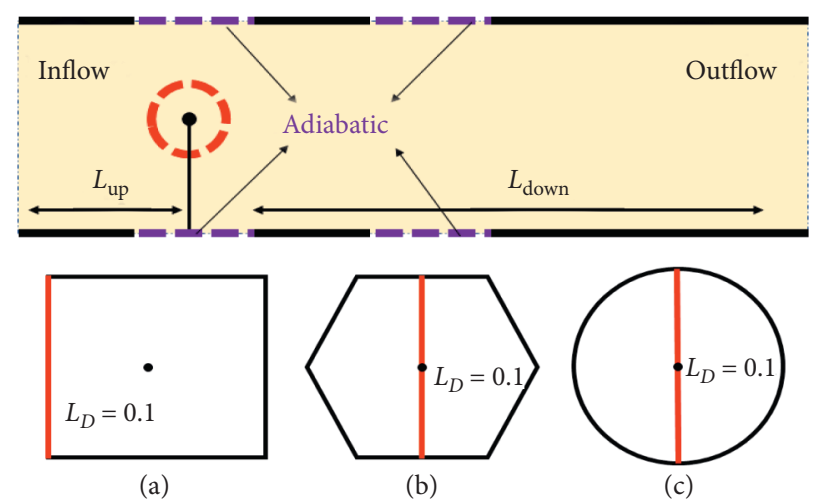

FIgURE 1: Schematic diagram of the problem: (a) square; (b) hexagon; (c) circle.

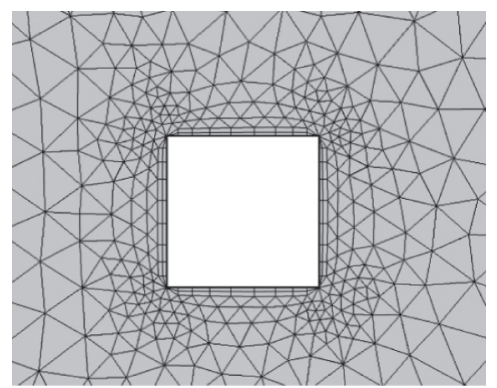

(a)

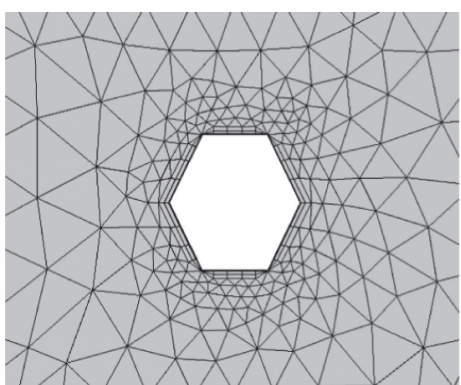

(b)

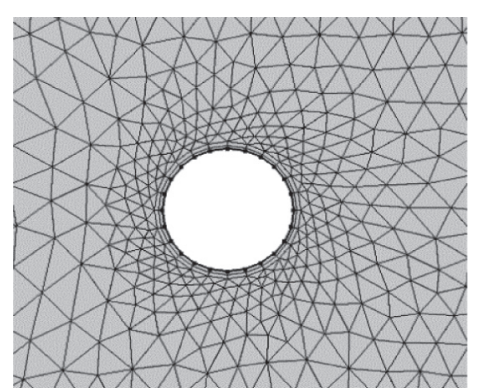

(c)

Figure 2: Complex computational grids at coarse level: (a) square; (b) hexagon; (c) circle.

TABLE 1: Grid convergence study for square cylinder.

\begin{tabular}{|c|c|c|c|c|c|}
\hline \#RL & \#EL & DOF & $C_{D}$ & $C_{L}$ & $\mathrm{Nu}_{\mathrm{avg}}$ \\
\hline 1 & 1,126 & 8,483 & 6.8482 & 0.0356 & 4.8973 \\
\hline 2 & 1,790 & 13,396 & 6.9111 & 0.0619 & 4.9782 \\
\hline 3 & 2,846 & 20,782 & 6.9246 & 0.0706 & 5.0401 \\
\hline 4 & 5,160 & 36,943 & 6.9333 & 0.0720 & 5.1123 \\
\hline 5 & 7,850 & 55,357 & 6.9347 & 0.0731 & 5.1496 \\
\hline 6 & 13,648 & 94,160 & 6.9359 & 0.0728 & 5.1807 \\
\hline 7 & 30,900 & 212,318 & 6.9389 & 0.0726 & 5.2426 \\
\hline 8 & 72,496 & 493,199 & 6.9397 & 0.0721 & 5.2791 \\
\hline
\end{tabular}

\section{Results and Discussions}

This work endeavors in three different cross-sectional cylinders with significant boundary conditions to elucidate the impact of non-Newtonian fluid flow and heat transfer behavior. The results shown in this study cover the range of parameters as: $0.4 \leq n \leq 1.8,10 \leq \mathrm{Re} \leq 50,0 \leq \mathrm{Bn} \leq 50,0.7 \leq$ $\operatorname{Pr} \leq 10$, and $1 \leq \mathrm{Gr} \leq 10$, respectively. Here is a comment on the choice of these ranges. The value of the power law index is encountered in many products such as suspension and polymer fluids found in industrial practices. Moreover, Bn are considered adequate for determining their influence on flow and heat transfer characteristics. The lowest value of $(\mathrm{Bn}=0)$ is Newtonian and the fluid in the very wide $(\mathrm{Bn} \longrightarrow \infty)$ is plug-like and heat is transmitted only via conduction which is slightly increased by piston-like fluid motion. The selection of the range of parameters for present work is based on a combination of the actual material characteristics and the anticipated fluid limiting conditions. Extensive results are discussed in the ensuring sections on lengths entrance, velocity profile and temperature, yield surfaces, and $\mathrm{Nu}_{\mathrm{avg}}$. It is, however, edifying first to determine the accuracy of the existing numeric assumptions and this objective is accomplished by presenting a number of benchmarks for a number of limiting circumstances and comparing the results available in literature.

4.1. Power Law Model. The velocity distribution illuminated in Figure 3 with varying cylinder shapes at Reynolds $\mathrm{Re}=$ 20 with Newtonian fluid $n=1$ is restricted. Since the velocity of the parabola is induced at inlet, and other boundaries are kept in no-slip conditions, velocity variation close to channel obstacles is observed. A conclusion is 
TABLE 2: Grid convergence study for hexagonal cylinder.

\begin{tabular}{|c|c|c|c|c|c|}
\hline \#RL & \#EL & DOF & $C_{D}$ & $C_{L}$ & $\mathrm{Nu}_{\mathrm{avg}}$ \\
\hline 1 & 1,098 & 8,279 & 6.1080 & -0.0019 & 4.6590 \\
\hline 2 & 1,796 & 13,413 & 6.1088 & 0.0004 & 4.7139 \\
\hline 3 & 2,742 & 20,061 & 6.1096 & 0.0005 & 4.7385 \\
\hline 4 & 4,984 & 35,706 & 6.1116 & 0.0016 & 4.7873 \\
\hline 5 & 7,666 & 54,068 & 6.1124 & 0.0017 & 4.7847 \\
\hline 6 & 13,298 & 91,768 & 6.1128 & 0.0018 & 4.8005 \\
\hline 7 & 30,388 & 208,777 & 6.1135 & 0.0019 & 4.8355 \\
\hline 8 & 71,232 & 484,604 & 6.1135 & 0.0019 & 4.8517 \\
\hline
\end{tabular}

TABLE 3: Grid convergence study for circular cylinder.

\begin{tabular}{lccccc}
\hline$\# \mathrm{RL}$ & \#EL & $\mathrm{DOF}$ & $C_{D}$ & $C_{L}$ & $\mathrm{Nu}_{\mathrm{avg}}$ \\
\hline 1 & 962 & 7,378 & 5.5349 & -0.0075 & 4.8564 \\
2 & 1,590 & 12,009 & 5.4785 & -0.0087 & 4.9292 \\
3 & 2,426 & 17,918 & 5.5207 & -0.0036 & 4.9190 \\
4 & 4,540 & 32,683 & 5.5510 & -0.0019 & 4.9243 \\
5 & 6,716 & 47,611 & 5.5538 & -0.0018 & 4.9283 \\
6 & 11,796 & 81,603 & 5.5605 & -0.0015 & 4.9297 \\
7 & 27,194 & 197,374 & 5.5754 & -0.0008 & 4.9286 \\
8 & 65,288 & 444,870 & 5.5786 & -0.0008 & 4.9292 \\
\hline
\end{tabular}

TABLE 4: Validation of code for comparison of drag and lift coefficients.

\begin{tabular}{lcc}
\hline Coefficients of fluid forces & Schaefer and Turek [42] & Present study \\
\hline$C_{D}$ & 5.5785 & 5.5785 \\
$C_{L}$ & 0.0106 & 0.0106 \\
\hline
\end{tabular}

reached that the parabolic nature of velocity profiles is similar in the entry. Figure 4 is plotted to evaluate pressure variation across the physical domain, particularly in vicinity of circular obstacle and constant $\mathrm{Re}=20$. From the figure, it is seen that pressure exhibits optimized nonlinear (power law, Bingham, and Herschel-Bulkley) fluids behavior close to the obstacle and gets linear downstream in channel flow as expected. Here, the optimum pressure is observed to have maximum value in front of the obstruction that interacts with fluid. It also appears that its pressures become linear when the fluid passes over the obstacle.

Figure 5 shows the effects of the shape of cylinder on $C_{D}$ and $C_{L}$ against $n$ from 0.4 to 1.6 covering a wide range of Newtonian, shear-thinning (thixotropic), and shearthickening (rheopectic) fluids. The reductions in the values of $C_{D}$ and $C_{L}$ are observed from square to circle cylinders. Moreover, reduction in power law index results in lowering the apparent fluid's viscosity beside the cylinder, thereby reducing the frictional drag strength. The shape effects for Newtonian fluid $(n=1)$ against Re are illustrated in Figure 6. Furthermore, the power law index influences the total drag coefficient which is decreasing gradually as the Re increases from 10 to 50 . In Figure 7, the effect of drag and lift coefficients on obstacle shapes was shown; with increasing Prandtl numbers, $C_{D}$ and $C_{L}$ decrease. Both coefficients produce lower values for the case of circular cylinder as compared with the other two shapes.
The changes in the flow field because of the parametric values of $n, \mathrm{Re}$, and $\mathrm{Pr}$ significantly impact the $\mathrm{Nu}_{\mathrm{avg}}$ over the surface of cylinders. Towards this end, we presented in this section the effects on the $\mathrm{Nu}_{\text {avg }}$ for the different shapes of the cylinder for Pr, $n$, and Re. Figure 8(a) shows that increasing the $\mathrm{Pr}$ gives rise to an increment in the $\mathrm{Nu}_{\mathrm{avg}}$. The dependence of $\mathrm{Nu}_{\mathrm{avg}}$ on $n$ and $R e$ for three different cylinders is shown in Figures $8(\mathrm{~b})$ and $8(\mathrm{c}) . \mathrm{Nu}_{\mathrm{avg}}$ increases as the $\mathrm{Re}$ increases because the thermal boundary layer is progressively thinning. In addition, an increase in shear-thinning (decreased value of $\mathrm{n}$ ) also improves the rate of thermal flow, due to the reduction of the apparent fluid viscosity because of steep gradients close to the submerged cylinders.

4.2. Bingham Model. In this case, the flow field comprises the yielded and unyielded zones, which vary with the choice of Bingham fluid which is nondimensional analog of yield stress. Figure 9 illustrates the areas where fluid moves like a rigid body in unyielding (plug) zones. The viscosity increases as the yield stress in the Bingham fluid gradually increases. In the vicinity of the submerged cylinder there is always a yielded region. Bingham fluid acts in the center of the channel like a solid. Figure 10 shows the isotherms around the cylinders for the Newtonian case at fixed Re. The isothermal profile reflects the physical phenomena observed through the analysis of patterns of streamlines. More thermal contours are crowded near the curved surface than 


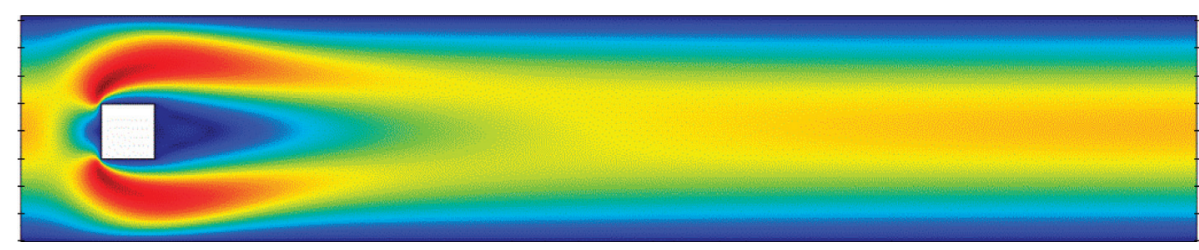

(a)

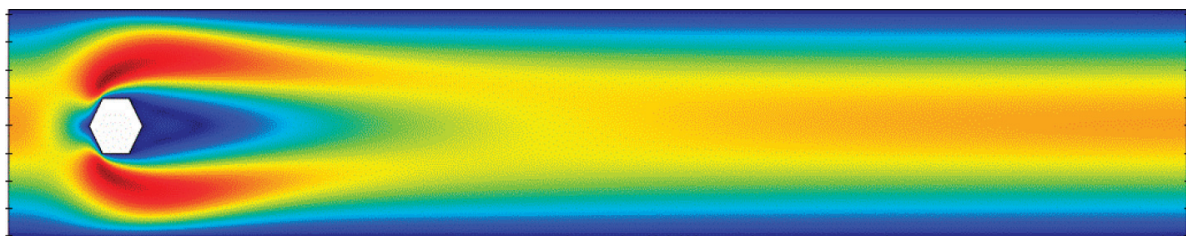

(b)

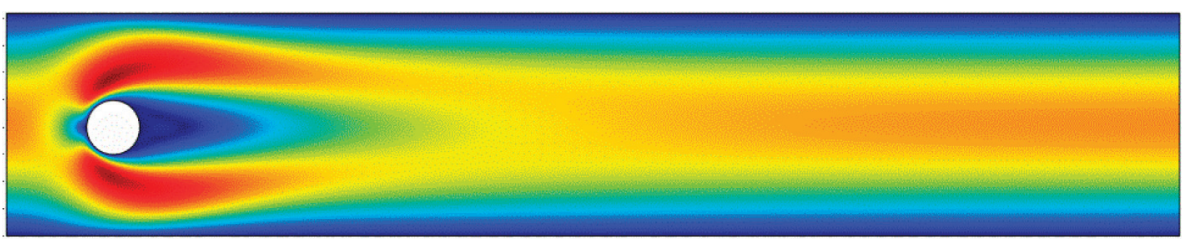

(c)

Figure 3: Shape effects on velocity profile for $n=1, \operatorname{Pr}=5$, and $\operatorname{Re}=20$. (a) Square shape cylinder; (b) hexagon shape cylinder; (c) circular shape cylinder.

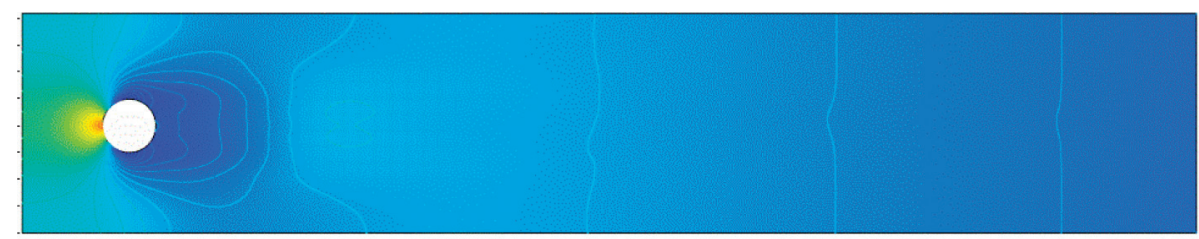

(a)

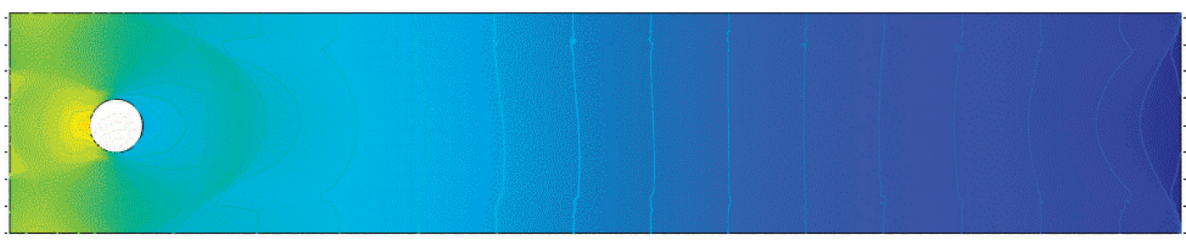

(b)

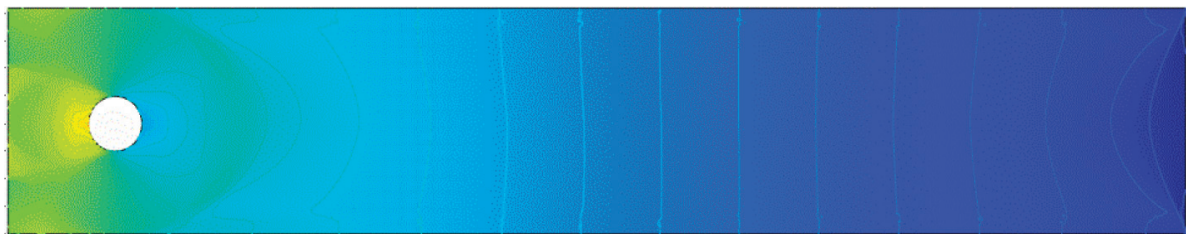

(c)

Figure 4: Fluid effects on pressure profile for $\mathrm{Re}=20$. (a) Power law fluid $(n=0.4)$. (b) Bingham fluid $(\mathrm{Bn}=20)$. (c) Herschel-Bulkley fluid $(\mathrm{Bn}=20, n=0.4)$.

on the flat surface, which leads to a higher $\mathrm{Nu}_{\text {avg }}$ on the curved surface. The crowds of temperature contours depend on the $\mathrm{Bn}$ and $\mathrm{Pr}$

The trend of $C_{D}$ and $C_{L}$ based on the shape of cylinders versus Bn can be seen in Figure 11. There is a linear growing profile for drag coefficient for all shapes. However, for a square cylinder the $C_{D}$ is higher as compared with the other cases because the fluid forces dominate at the surface of square cylinder. The $C_{L}$ varies nonlinearly for all cylinders; for the square cylinder, however, the $C_{L}$ decreases after a certain Bn threshold with an increase in the Bn. However, quantitative analysis of $C_{D}$ and $C_{L}$ for different $R e$ is 


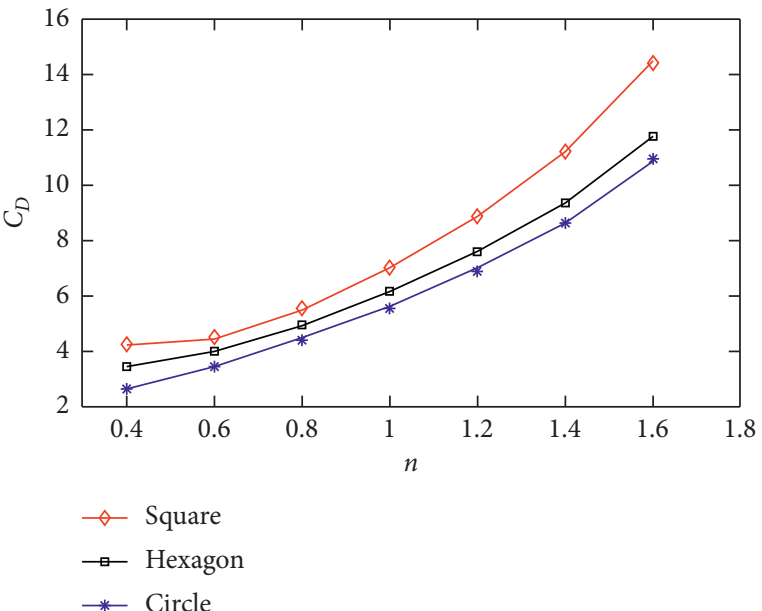

(a)

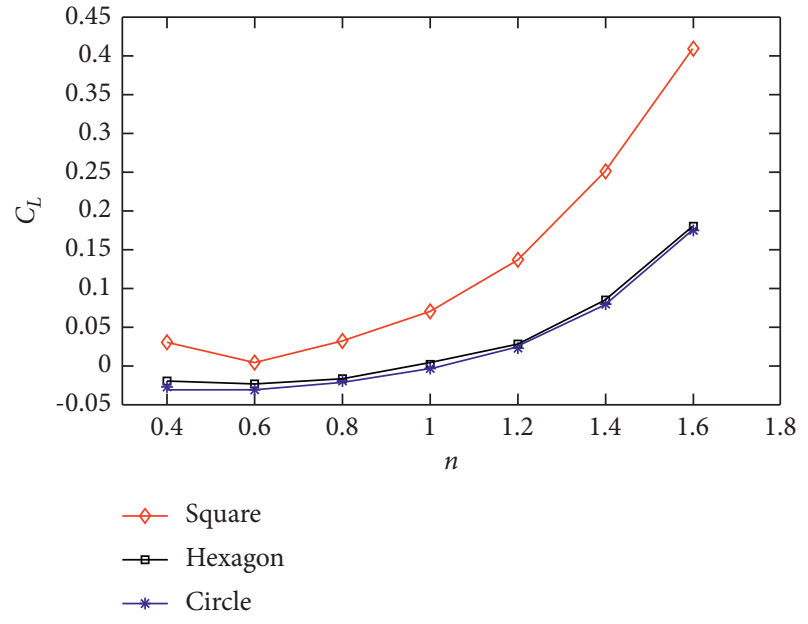

(b)

Figure 5: (a) Drag coefficient and (b) lift coefficient against $n$ with $\operatorname{Pr}=5$ and $\operatorname{Re}=20$.

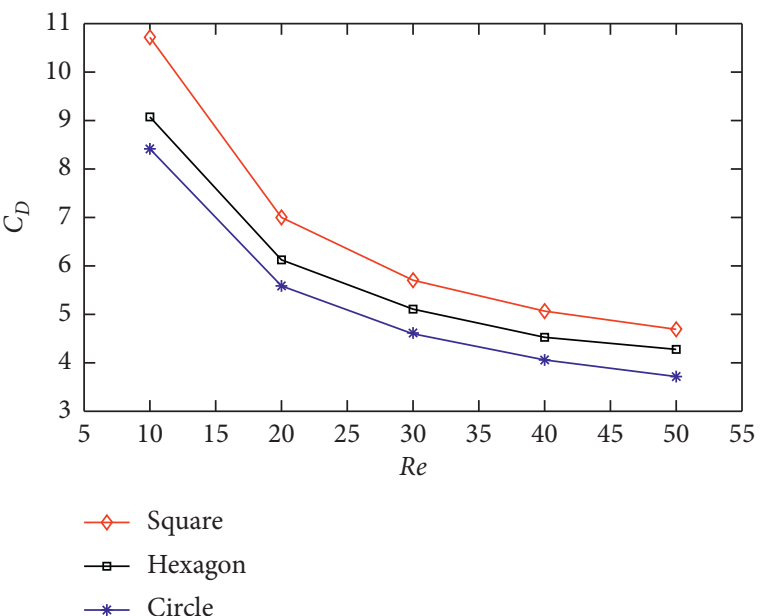

(a)

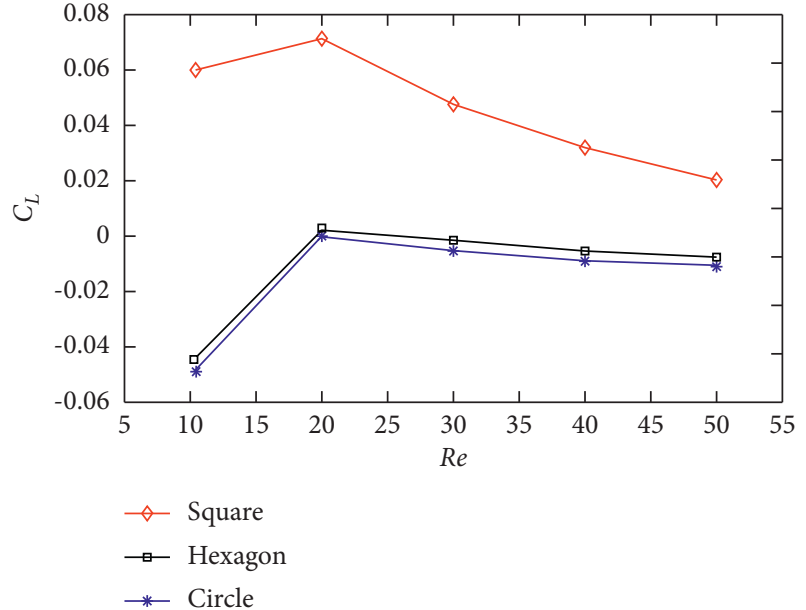

(b)

Figure 6: (a) Drag coefficient and (b) lift coefficient against Re with $\operatorname{Pr}=5$ and $n=1$.

presented in Table 5. Table 6 shows that, in the case of three shaped cylinders, maximum reduction is observed for all $\mathrm{Bn}$ values. In addition, the maximum reduction can be seen at $\mathrm{Bn}=0$ for all cylinder combinations. In the range $0 \leq \mathrm{Bn} \leq 50$, for all configurations that approach their corresponding minimum values, the values of a percent reduction decrease.

Figure 12 reveals the disparity of the $\mathrm{Nu}_{\text {avg }}$ based on the shapes of cylinder and with the $B n$. The $\mathrm{Nu}_{\text {avg }}$ has been shown to dominate in case of square cylinder.

4.3. Herschel-Bulkley Model. The fluid model Herschel-Bulkley combines the characteristics of Power Law and Bingham models. The fluid flow of Herschel-Bulkley thus shares the features of power law and of Bingham fluid. The effect on the flow components is similar from the power index and Bingham number. For this reason, only those flow characteristics over the cylinder that were not described above will be discussed in this case. Such as the Bingham fluid, a fluid region is formed around the cylinder when there is a flow over the cylinder, while the medium is a rigid substance on the periphery. The fluid region is mainly based on the number of Bingham: the larger the amount of Bingham, the lesser the region of fluid.

The size depends simultaneously on the power index: the lower the $n$, the smaller the fluid region. It can thus be concluded that a perturbation of the cylinders is reduced if the rheology of the fluids is non-Newtonian, if the number of the Bingham and/or the power index is lower. In strongly nonNewtonian fluids, dependence on the drag and kinematic features of the flow is less significant than in Newtonian fluids. The responsiveness of the flow properties to relative velocity changes is weakened as the non-Newtonian fluid properties 

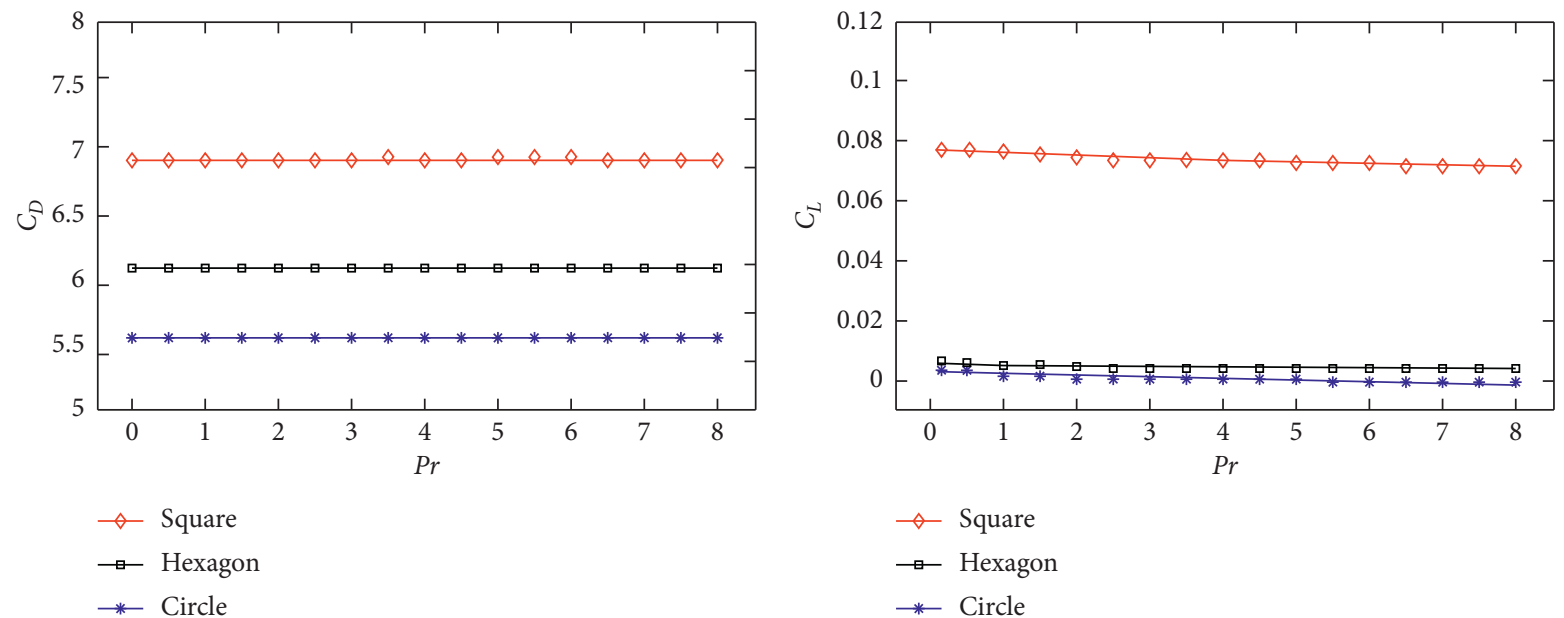

(a)

(b)

Figure 7: (a) Drag coefficient and (b) lift coefficient against Pr with $n=1$ and $\operatorname{Re}=20$.
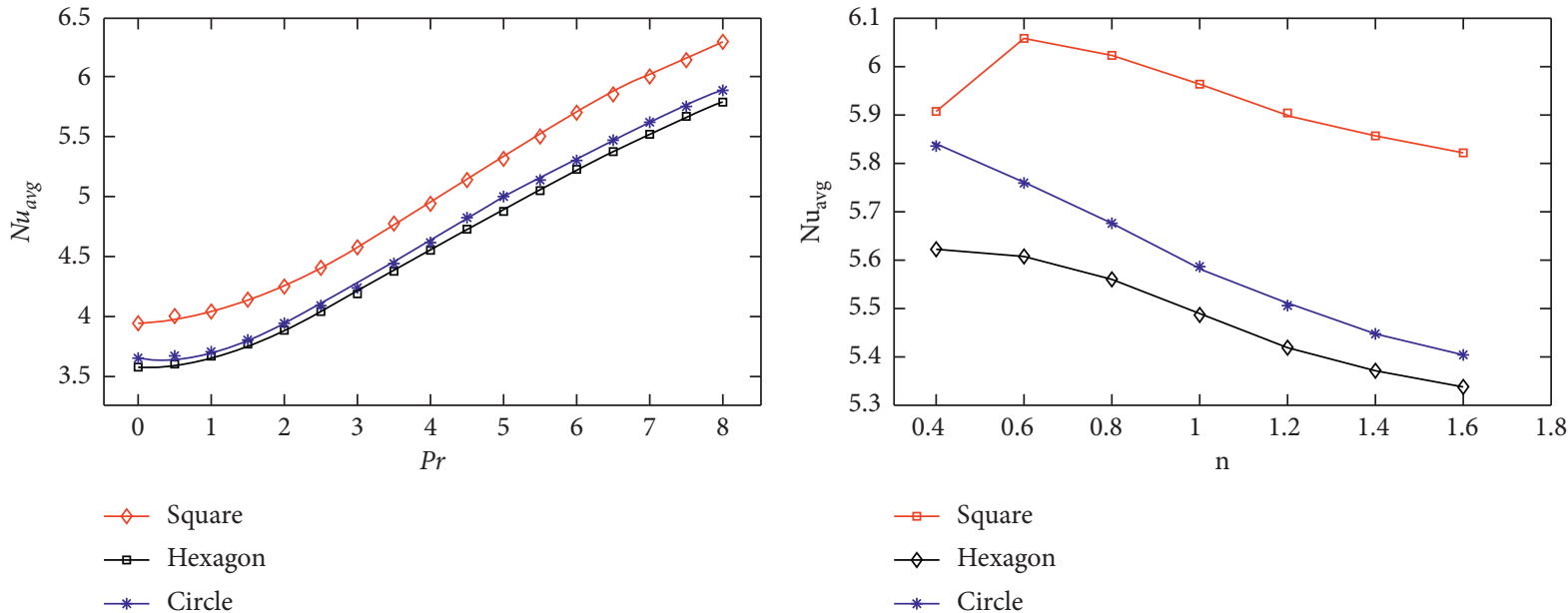

(a)

(b)

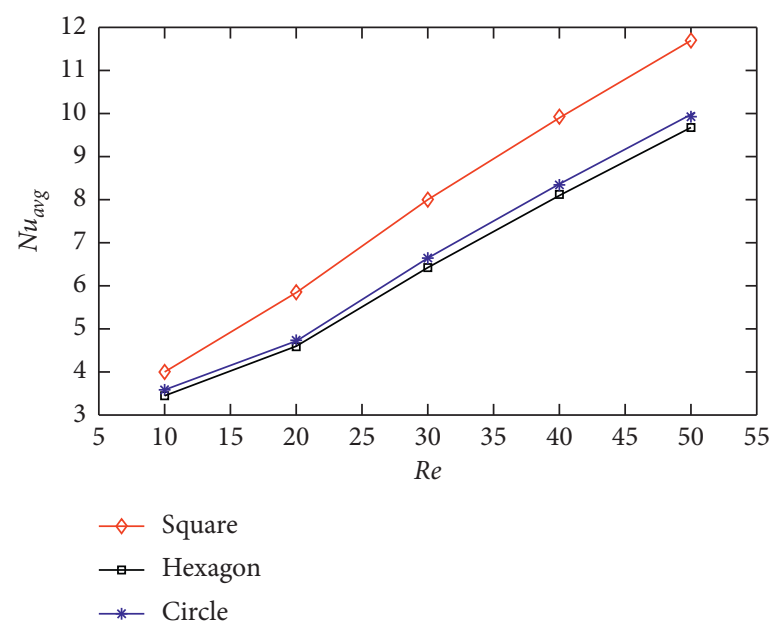

(c)

Figure 8: (a): Average Nusselt number $\left(\mathrm{Nu}_{\text {avg }}\right)$ against $\operatorname{Pr}$ with $n=1$ and $\mathrm{Re}=20$. (b) Average Nusselt number $\left(\mathrm{Nu}_{\text {avg }}\right)$ against $n$ with $\operatorname{Pr}=5$ and $\operatorname{Re}=20$. (c) Average Nusselt number $\left(\mathrm{Nu}_{\mathrm{avg}}\right)$ against Re with $n=1$ and $\operatorname{Pr}=5$. 


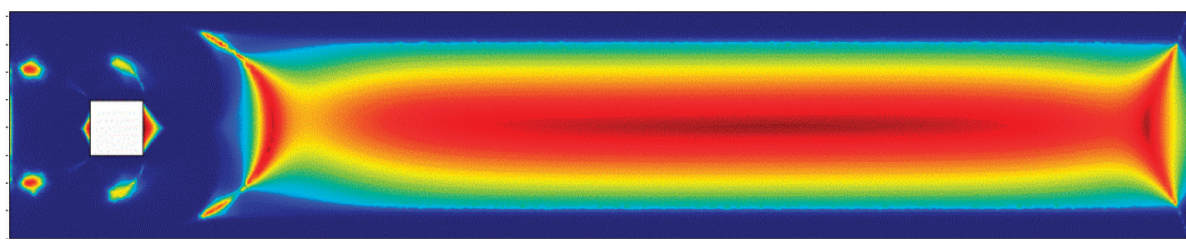

(a)

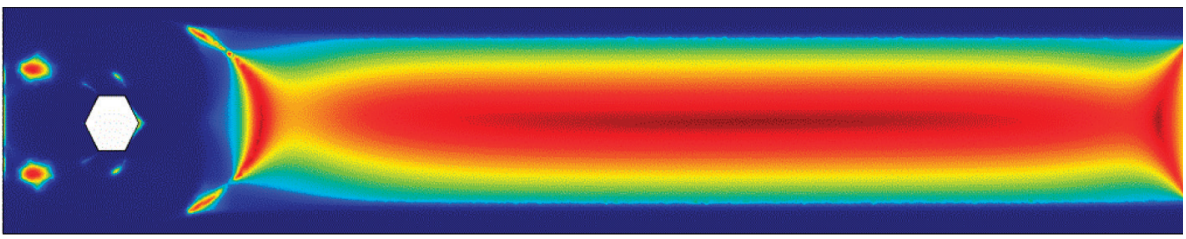

(b)

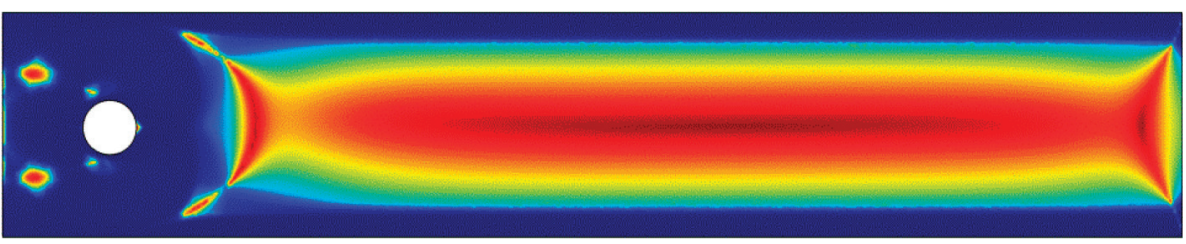

(c)

FIGURE 9: Shape effects on viscosity field for $\mathrm{Bn}=20$ and $\mathrm{Re}=20$. (a) Square shape cylinder; (b) hexagon shape cylinder; (c) circular shape cylinder.

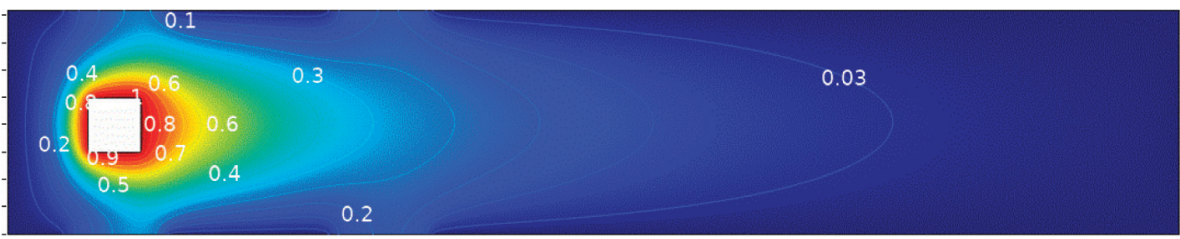

(a)

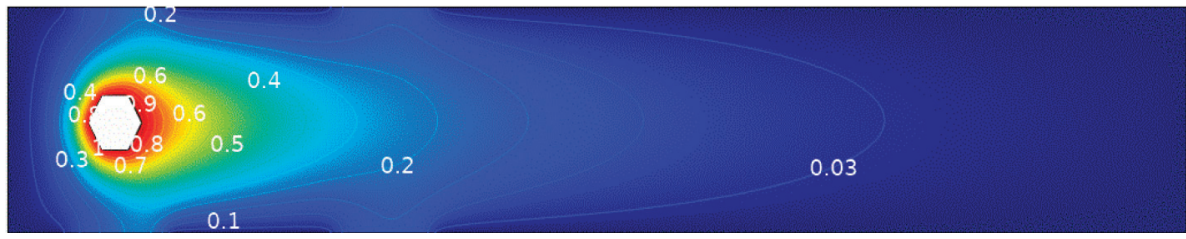

(b)

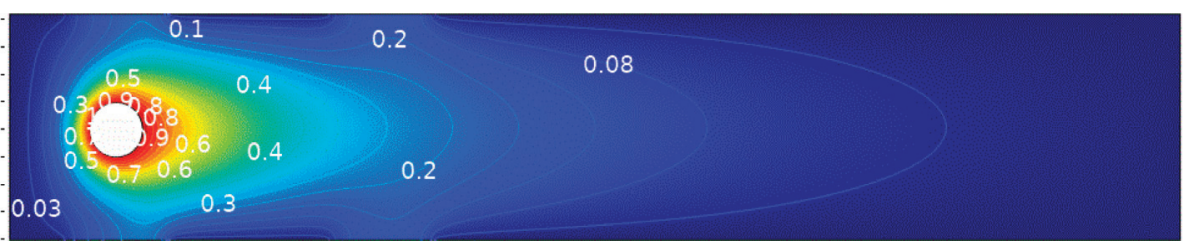

(c)

Figure 10: Shape effects on isotherm contour for $\mathrm{Bn}=20$ and $\mathrm{Re}=20$. (a) Square shape cylinder; (b) hexagon shape cylinder; (c) circular shape cylinder.

increase. Figure 13 reveals the characteristics of drag and lift coefficient against Bingham number for different fluid properties over the different cylinders. The drag trend for Bn is the same across the fluid, but the drag values for the rheopectic fluid are higher as the boundaries are nonsmooth compared to the thixotropic fluid. The lift values demonstrate an increasing trend for $\mathrm{Bn}$ from 0 to 10 and reveal a decreasing trend for a further increase in the Bingham number for each fluid case. Figure 14 reveals the effects of cylinder shapes on average Nusselt number against Bn for complex 


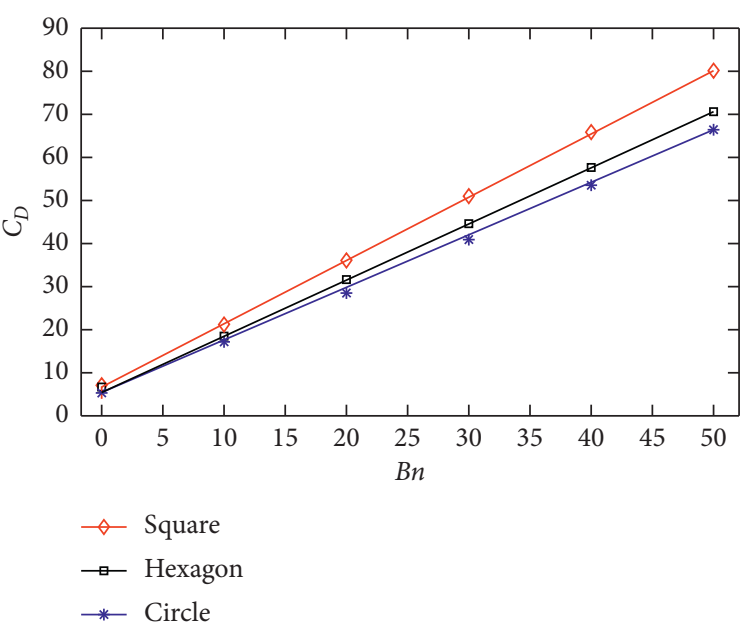

(a)

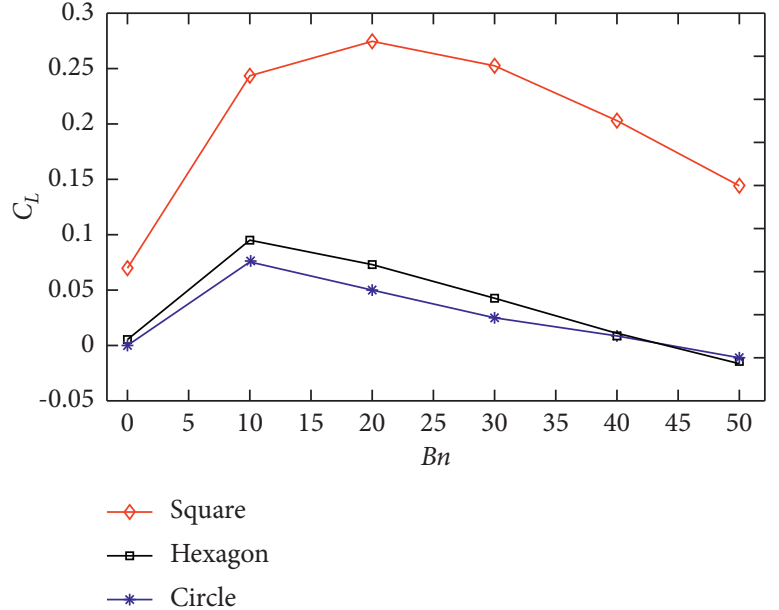

(b)

Figure 11: (a) Drag coefficient $C_{D}$ and (b) lift coefficient $C_{L}$ against $\mathrm{Bn}$ with $\operatorname{Pr}=5$ and $\operatorname{Re}=20$.

TABLE 5: Impact on drag and lift coefficients against Bn for different Re values.

\begin{tabular}{|c|c|c|c|c|c|c|}
\hline \multirow{2}{*}{$\mathrm{Bn}$} & \multicolumn{2}{|c|}{$\mathrm{Re}=10$} & \multicolumn{2}{|c|}{$\mathrm{Re}=30$} & \multicolumn{2}{|c|}{$\operatorname{Re}=50$} \\
\hline & $C_{D}$ & $C_{L}$ & $C_{D}$ & $C_{L}$ & $C_{D}$ & $C_{L}$ \\
\hline 0 & 8.428736 & -0.04927 & 4.571563 & -0.00557 & 3.694473 & -0.01109 \\
\hline 10 & 58.36013 & 0.120413 & 9.431011 & 0.044435 & 5.201851 & 0.015601 \\
\hline 20 & 107.898 & 0.001741 & 14.68912 & 0.044090 & 6.969524 & 0.025137 \\
\hline 30 & 156.8559 & -0.13567 & 20.02938 & 0.030733 & 8.793285 & 0.028560 \\
\hline 40 & 205.5070 & -0.29718 & 25.40788 & 0.015660 & 10.65577 & 0.026068 \\
\hline 50 & 253.8652 & -0.44502 & 30.81171 & 0.003527 & 12.53580 & 0.020911 \\
\hline
\end{tabular}

Table 6: Percentage reduction in drag coefficient: square versus hexagonal and circular case.

\begin{tabular}{lccccc}
\hline Bn & Square & Hexagon & \% reduction & Circle & \% reduction \\
\hline 0 & 6.9397 & 6.1135 & 14.94 & 5.5786 & 11.2657 \\
5 & 13.9553 & 12.0237 & 14.41 & 17.2796 & 19.51 \\
10 & 21.4478 & 18.4166 & 14.13 & 23.3732 & 19.43 \\
15 & 28.9459 & 24.8896 & 14.01 & 29.5111 & 19.25 \\
20 & 36.4354 & 31.4094 & 13.79 & 35.6571 & 19.00 \\
25 & 43.8990 & 37.9431 & 13.57 & 41.8024 & 18.77 \\
30 & 51.3235 & 44.4747 & 13.34 & 5443 & 18.55 \\
35 & 58.7175 & 51.0029 & 13.14 & 60.1993 & 18.17 \\
40 & 66.0861 & 57.5283 & 12.79 & 66.3107 & 18.03 \\
45 & 73.4365 & 64.0466 & 12.64 & 17.90 \\
50 & 80.7721 & 70.5589 & &
\end{tabular}

fluids. Figure 15 shows the variation of the $\mathrm{Nu}_{\mathrm{avg}}$ with $\mathrm{Bn}$ on both shape cylinders and the $\mathrm{Gr}$. The $\mathrm{Nu}_{\text {avg }}$ increases with $\mathrm{Gr}$ as usual.
A line graph is shown in Figure 16 to depict the impact of rheology of fluid on velocity profiles. The velocity profile changes as the yield stress increases, from a parabola to a flat 


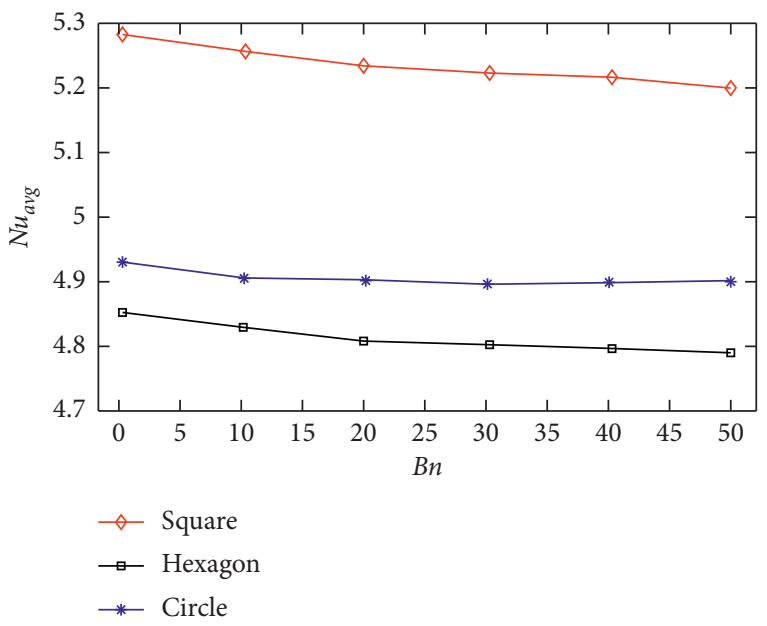

Figure 12: Average Nusselt number $\left(\mathrm{Nu}_{\text {avg }}\right)$ against $\mathrm{Bn}$ with $\mathrm{Re}=20$ and $\operatorname{Pr}=5$.
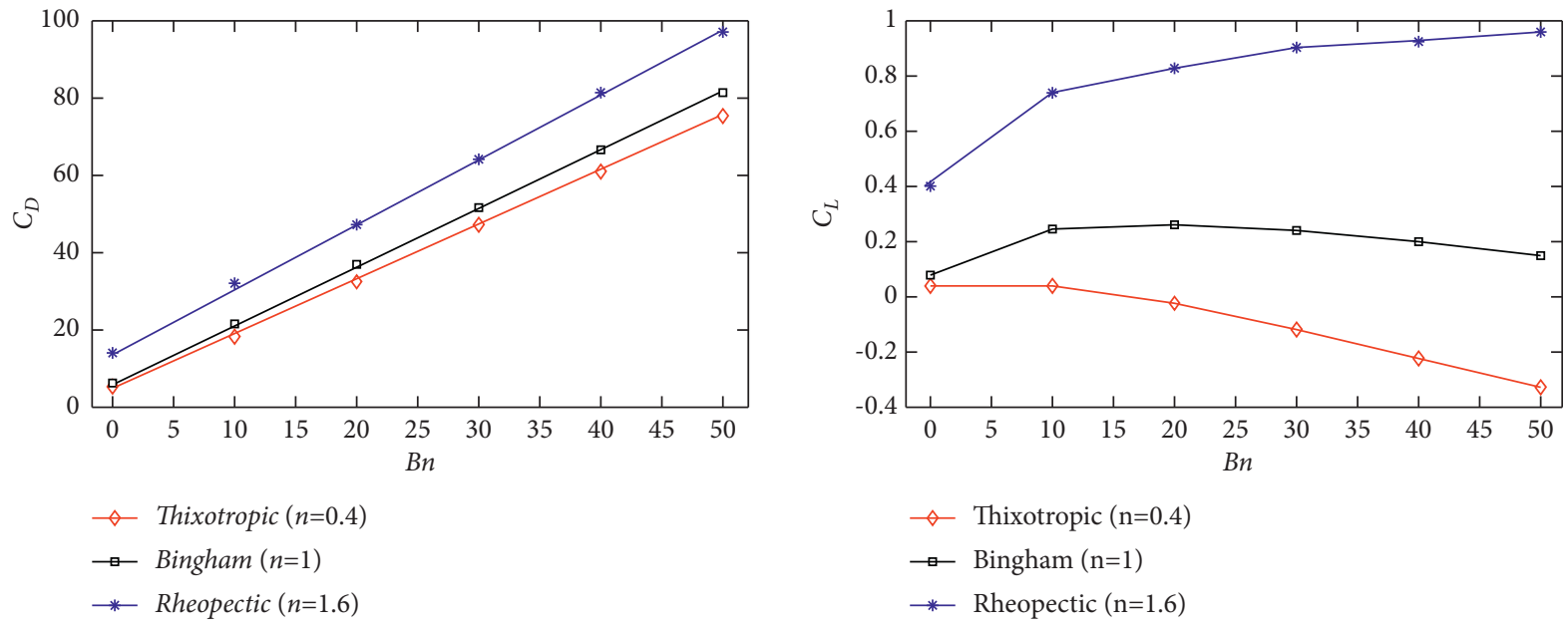

(a)
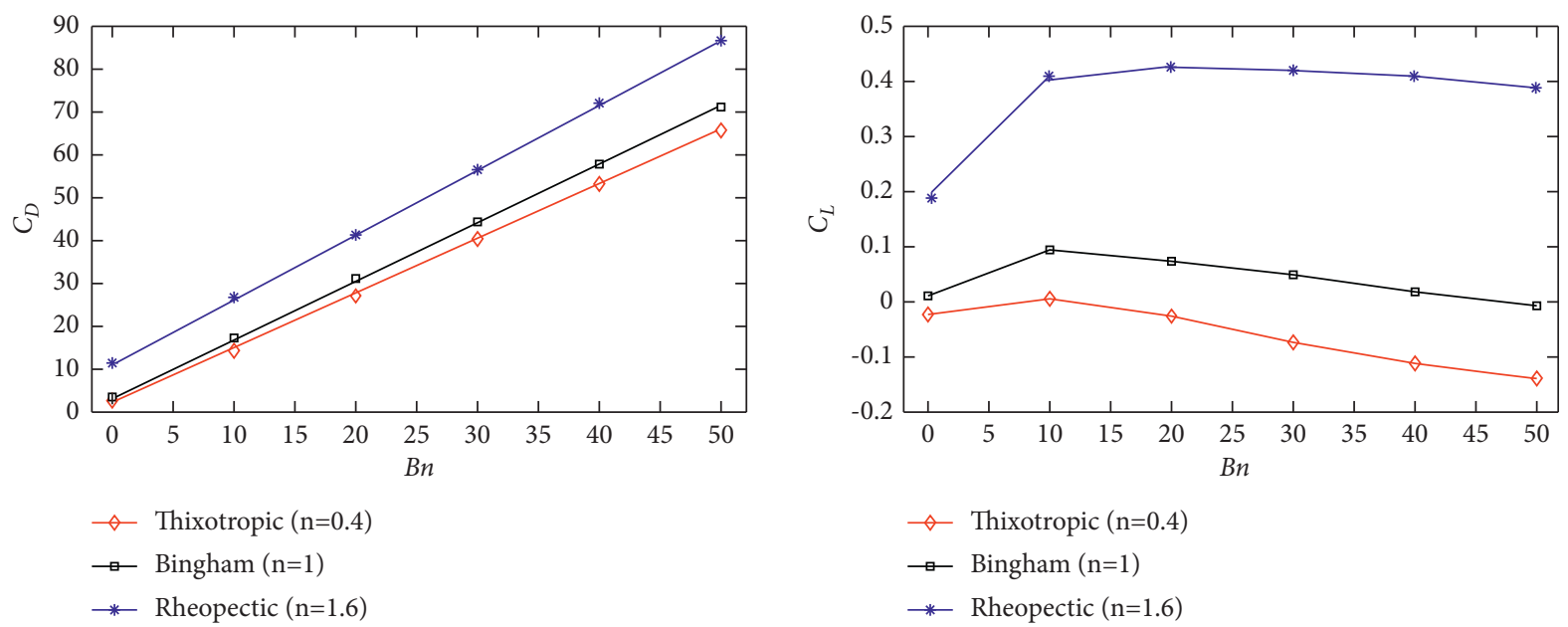

(b)

Figure 13: Continued. 

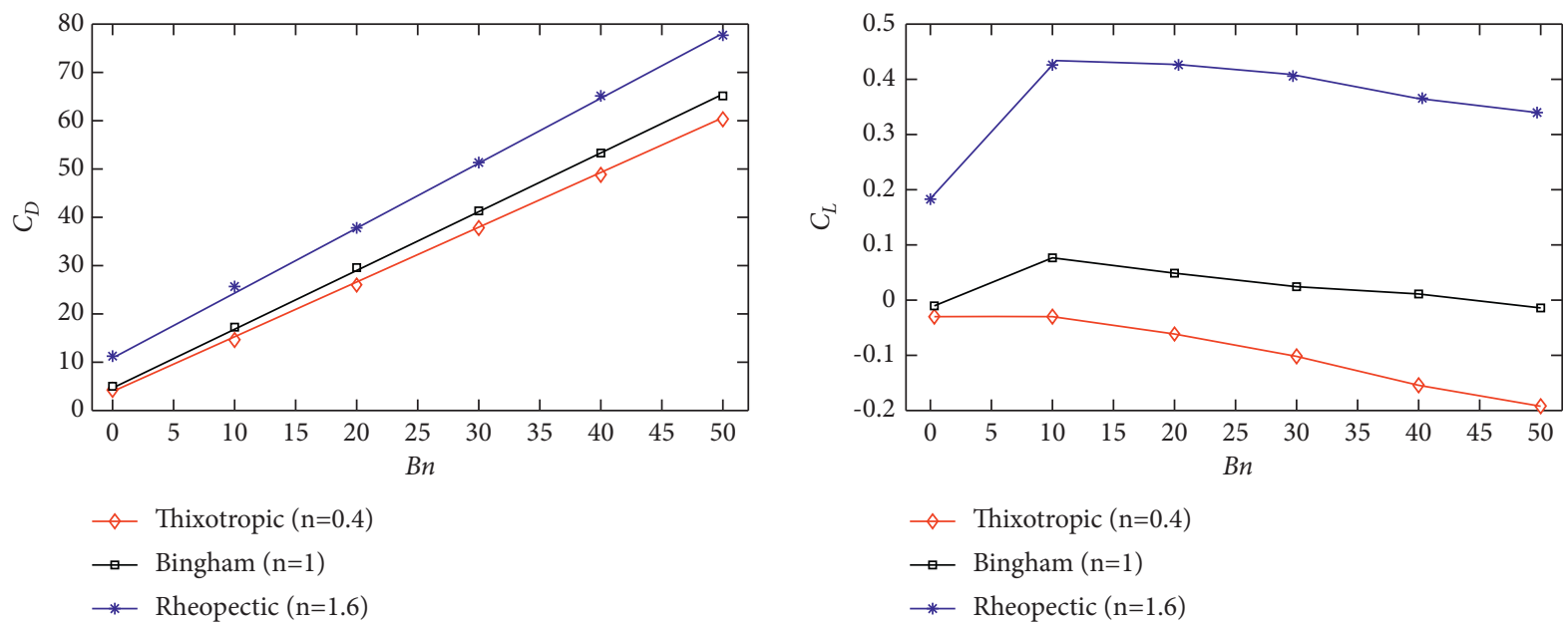

(c)

Figure 13: Drag and lift coefficients against Bn with $\operatorname{Pr}=5$ and $\operatorname{Re}=20$. (a) Square cylinder; (b) hexagonal cylinder; (c) circle cylinder.
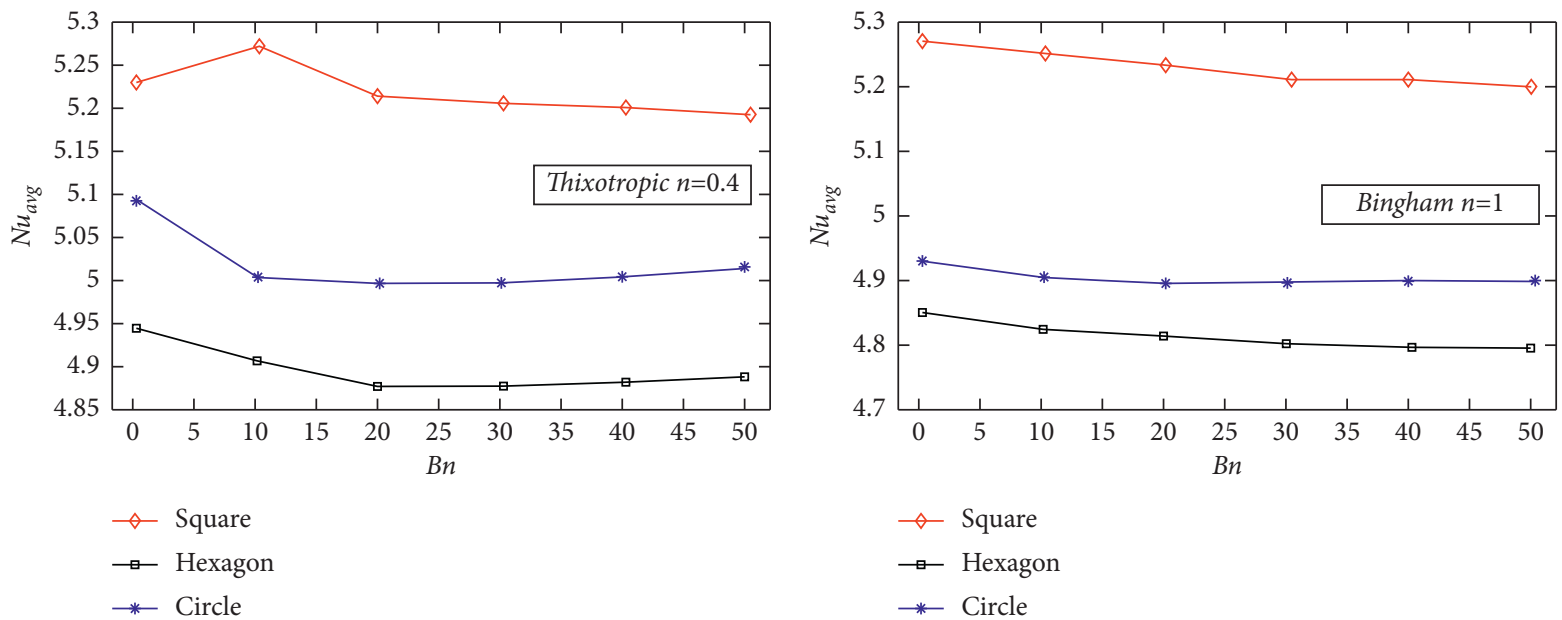

(a)

(b)

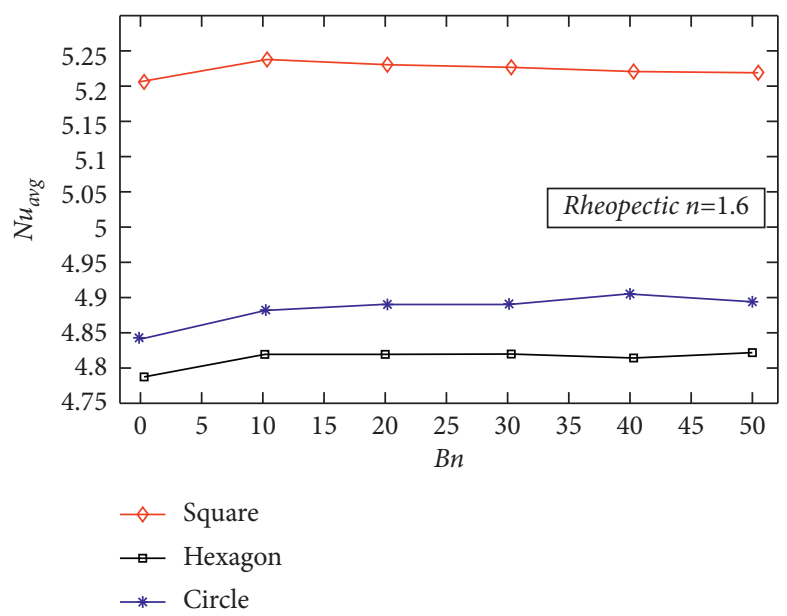

(c)

Figure 14: Average Nusselt number $\left(\mathrm{Nu}_{\mathrm{avg}}\right)$ for different fluids against $\mathrm{Bn}$ with $\mathrm{Pr}=5$ and $\mathrm{Re}=20$. (a) Thixotropic $(n=0.4)$; (b) Bingham $(n=1)$; (c) rheopectic $(n=1.6)$. 


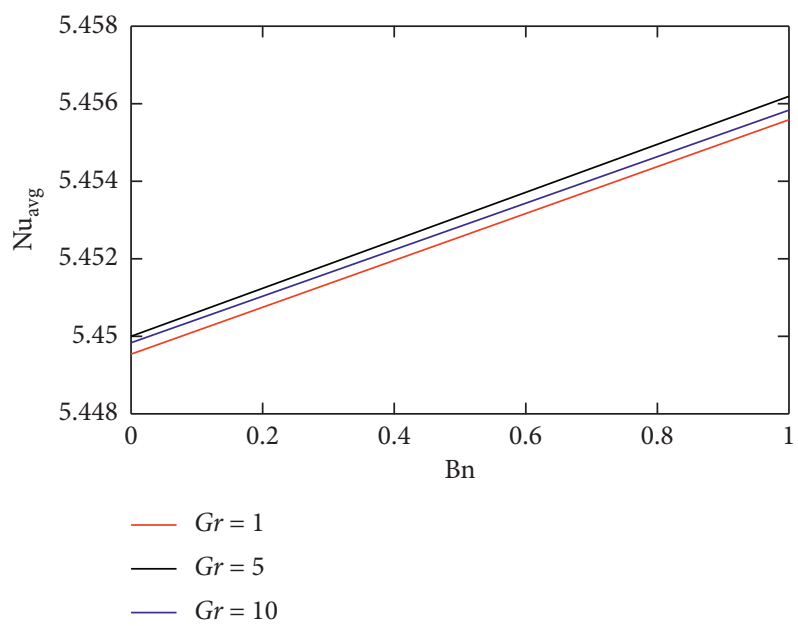

FIgURE 15: Impact of average Nusselt number $\left(\mathrm{Nu}_{\text {avg }}\right)$ against $\mathrm{Bn}$ for different $\mathrm{Gr}$ values.

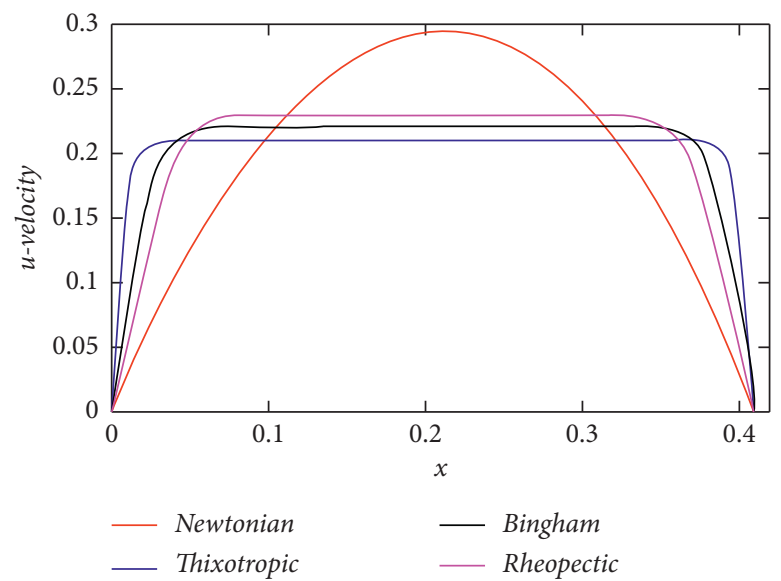

FIgURE 16: Velocity profile for various fluid models at $x=2$ with $\operatorname{Re}=20$.

plateau in the channel central region, which represents the unyielded material.

\section{Conclusions}

In this manuscript, extensive computations have been carried out to elucidate the thermal flow features based on the topology of the obstacles. The results revealed herein enhance over the following varying ranges of nondimensional parameters: $n$ from 0.4 to $1.6, \mathrm{Bn}$ from 0 to 50 , Re from 10 to $50, \operatorname{Pr}$ from 0.7 to 10 , and Gr from 1 to 10 , respectively. In nonlinear fluid, $C_{D}$ decreases from square to circle by order to optimize cylinder. The results for the development and completion of the velocity profile and thermal flow and $\mathrm{Nu}_{\mathrm{avg}}$ for three typical shapes of partially insulated cylinders are detailed. The main findings include the following:

(i) Drag and lift coefficients increase against $n$ and $\operatorname{Pr}$ while they decrease along Re over all the topologies of cylinders (ii) For the Newtonian case, reduction in $C_{D}$ is maximum while reduction is decreasing for increasing the $\mathrm{Bn}$

(iii) The rate of thermal flow tends to increase as the Re values increase due to a decline in the $n$

(iv) The $\mathrm{Nu}_{\text {avg }}$ increases with increasing both $\mathrm{Bn}$ and $\mathrm{Gr}$

(v) The velocity profile shifts from a parabolic to a smooth plateau in the center along the channel when the yield stress increases indicating a plug zone in the center of the channel

\section{Nomenclature}

u: Dimensionless velocity

$\theta$ : Dimensionless temperature

$p$ : Dimensionless pressure

$m$ : Dimensional stress growth parameter

$n$ : Flow behavior index

$\rho$ : Density 
g: Gravitational acceleration

$L_{D}$ : Reference length

\section{Greek}

$\tau_{y}: \quad$ Yield stress

$\mu_{p}: \quad$ Plastic viscosity

$\tau: \quad$ Stress tensor

$\dot{\gamma}: \quad$ Shear rate

$U_{\infty}$ : $\quad$ Reference velocity

Re: Reynolds number

Bn: Bingham number

Pr: $\quad$ Prandtl number

Gr: Grashof number

$F_{D}: \quad$ Drag force

$C_{D}: \quad$ Drag coefficient

$F_{L}: \quad$ Lift force

$C_{L}: \quad$ Lift coefficient

$N u_{\text {avg }}:$ Average Nusselt number

$N u_{\text {local }}$ : Local Nusselt number

$\nabla: \quad$ Gradient operator

$\alpha: \quad$ Thermal diffusivity

$v$ : $\quad$ Kinematic viscosity

\section{Abbreviations}

\#EL: $\quad$ Number of elements

\#DOF: Number of degrees of freedom.

\section{Data Availability}

The data underlying the results presented in the study are available within the article.

\section{Conflicts of Interest}

The authors state that there are no conflicts of interest.

\section{Acknowledgments}

This work was supported by HEC-Pakistan through NRPU Project No. 14038.

\section{References}

[1] C. Ditchfield, C. C. Tadini, R. K. Singh, and R. T. Toledo, "Velocity and temperature profiles, heat transfer coefficients and residence time distribution of a temperature dependent Herschel-Bulkley fluid in a tubular heat exchanger," Journal of Food Engineering, vol. 76, no. 4, pp. 632-638, 2006.

[2] R. Shyam, C. Sasmal, and R. P. Chhabra, "Natural convection heat transfer from two vertically aligned circular cylinders in power-law fluids," International Journal of Heat and Mass Transfer, vol. 64, no. 17, pp. 1127-1152, 2013.

[3] H. Laidoudi and M. Bouzit, "Mixed convection heat transfer from confined tandem circular cylinders in cross-flow at low Reynolds number," Mechanika, vol. 23, no. 4, pp. 522-527, 2017.

[4] H. Laidoudi and M. Bouzit, "Suppression of flow separation of power-law fluids flow around a confined circular cylinder by superimposed thermal buoyancy," Mechanika, vol. 23, no. 2, pp. 220-227, 2017.

[5] G. R. Kefayati and H. Tang, "Double-diffusive natural convection and entropy generation of Carreau fluid in a heated enclosure with an inner circular cold cylinder (Part I: heat and mass transfer)," International Journal of Heat and Mass Transfer, vol. 120, pp. 731-750, 2018.

[6] H. Laidoudi and M. Bouzit, "Mixed convection in Poiseuille fluid from an asymmetrically confined heated circular cylinder," Thermal Science, vol. 22, no. 2, pp. 821-834, 2018.

[7] H. Masoumi, M. S. Aghighi, A. Ammar, and A. Nourbakhsh, "Laminar natural convection of yield stress fluids in annular spaces between concentric cylinders," International Journal of Heat and Mass Transfer, vol. 138, pp. 1188-1198, 2019.

[8] F. Zafar and M. M. Alam, "Mixed convection heat transfer from a circular cylinder submerged in wake," International Journal of Mechanical Sciences, vol. 183, no. 1, pp. 83-88, 2020.

[9] H. Laidoudi, M. Helmaoui, M. Bouzit, and A. Ghenaim, "Natural convection of newtonian fluids between two concentric cylinders of a special cross-sectional form," Thermal Science, vol. 45, p. 190, 2020.

[10] R. P. Bharti, R. P. Chhabra, and V. Eswaran, "Steady flow of power law fluids across a circular cylinder," Canadian Journal of Chemical Engineering, vol. 84, no. 4, pp. 406-421, 2006.

[11] R. P. Bharti, R. P. Chhabra, and V. Eswaran, "Twodimensional steady Poiseuille flow of power-law fluids across a circular cylinder in a plane confined channel: wall effects and drag coefficients," Industrial \& Engineering Chemistry Research, vol. 46, no. 11, pp. 3820-3840, 2007.

[12] R. Shyam, M. Sairamu, N. Nirmalkar, and R. P. Chhabra, "Free convection from a heated circular cylinder in confined power-law fluids," International Journal of Thermal Sciences, vol. 74pp. 156-173, C, 2013.

[13] A. K. Baranwal and R. P. Chhabra, "Free convection in confined power-law fluids from two side-by-side cylinders in a square enclosure," Heat Transfer Engineering, vol. 37, no. 18, pp. 1521-1537, 2016.

[14] A. Pantokratoras, "Steady flow of power-law fluids across a circular rotating cylinder," Progress in Computational Fluid Dynamics, An International Journal, vol. 17, no. 4, pp. 239249, 2017.

[15] K. M. Gangawane and B. Manikandan, "Laminar natural convection characteristics in an enclosure with heated hexagonal block for non-Newtonian power law fluids," Chinese Journal of Chemical Engineering, vol. 25, no. 5, pp. 555-571, 2017.

[16] M. Asnaashari and A. Tohidi, "Conjugate heat transfer from a circular cylinder to a power-law non-Newtonian fluid," Heat Transfer - Asian Research, vol. 48, no. 4, pp. 1466-1482, 2019.

[17] A. Dhiman and R. Shyam, "Unsteady heat transfer from an equilateral triangular cylinder in the unconfined flow regime," ISRN Mechanical Engineering, vol. 2011, Article ID 932738, 13 pages, 2011.

[18] N. Nirmalkar and R. P. Chhabra, "Momentum and heat transfer from a heated circular cylinder in Bingham plastic fluids," International Journal of Heat and Mass Transfer, vol. 70, pp. 564-577, 2014.

[19] S. A. Patel and R. P. Chhabra, "Heat transfer in Bingham plastic fluids from a heated elliptical cylinder," International Journal of Heat and Mass Transfer, vol. 73, pp. 671-692, 2014.

[20] R. Mahmood, N. Kousar, M. Yaqub, and K. Jabeen, "Numerical simulations of the square lid driven cavity flow of bingham fluids using nonconforming finite elements coupled 
with a direct solver," Advances in Theoretical and Mathematical Physics, vol. 2017, Article ID 5210708, 9 pages, 2017.

[21] X. Liu, H. Cheng, J. Lin, C. Rong, M. Li, and H. Xu, "Study of the mechanism of fracture grouting in deeply buried rock strata based on bingham fluid slurry," Advances in Civil Engineering, vol. 2019, Article ID 6943239, 10 pages, 2019.

[22] P. Thakur, N. Tiwari, and R. P. Chhabra, "Forced convection in a Bingham plastic fluid from a heated rotating cylinder," Journal of Chemical Engineering of Japan, vol. 52, no. 9, pp. 730-742, 2019.

[23] B. Ren, L. Wang, H. Fan, K. Ding, K. Wang, and C. Jiang, "Unsteady approximate model of grouting in fractured channels based on bingham fluid," Geofluids Journal, vol. 16, 2021.

[24] C. Nouar, M. Lebouché, R. Devienne, and C. Riou, "Numerical analysis of the thermal convection for HerschelBulkley fluids," International Journal of Heat and Fluid Flow, vol. 16, no. 3, pp. 223-232, 1995.

[25] J.-G. Yoo and K.-W. Kim, "Numerical analysis of grease thermal elastohydrodynamic lubrication problems using the Herschel-Bulkley model," Tribology International, vol. 30, no. 6, pp. 401-408, 1997.

[26] C. Nouar, C. Desaubry, and H. Zenaidi, "Numerical and experimental investigation of thermal convection for a thermodependent Herschel-Bulkley fluid in an annular duct with rotating inner cylinder," European Journal of MechanicsB: Fluids, vol. 17, no. 6, pp. 875-900, 1998.

[27] C. Nouar, "Thermal convection for a thermo-dependent yield stress fluid in an axisymmetric horizontal duct," International Journal of Heat and Mass Transfer, vol. 48, no. 25-26, pp. 5520-5535, 2005.

[28] N. Labsi, Y. Benkahla, M. B. Feddaoui, and A. Boutra, "Viscous dissipation effect on the flow of a thermodependent herschel-bulkley fluid," Thermal Science, vol. 19, no. 5, pp. 1553-1564, 2015.

[29] M. A. Hassan, M. Pathak, and M. K. Khan, "Rayleigh-benard convection in herschel-bulkley fluid," Journal of Nonnewtonian Fluid Mechanics, vol. 226, pp. 32-45, 2015.

[30] A. A. Gavrilov, K. A. Finnikov, and E. V. Podryabinkin, "Modeling of steady herschel-bulkley fluid flow over a sphere," Journal of Engineering and Thermophysics, vol. 26, no. 2, pp. 197-215, 2017.

[31] L. Hermany, G. Lorenzini, R. J. Klein et al., "Constructal design applied to elliptic tubes in convective heat transfer cross-flow of viscoplastic fluids," International Journal of Heat and Mass Transfer, vol. 116, pp. 1054-1063, 2018.

[32] T. Hoshino, "“Analysis of the flow properties of a Herschel-Bulkley fluid using short back extrusion viscometry and considering time-dependent and stress growth behaviors," Rheologica Acta, vol. 54, pp. 809-819, 2020.

[33] P. S. B. Zdanski and M. Vaz, "A numerical method for simulation of incompressible three-dimensional Newtonian and non-Newtonian flows," Numerical Heat Transfer, Part B: Fundamentals, vol. 59, no. 5, pp. 360-380, 2011.

[34] W. Sarwar Abbasi, S. Ul Islam, L. Faiz, and H. Rahman, "Numerical investigation of transitions in flow states and variation in aerodynamic forces for flow around square cylinders arranged inline," Chinese Journal of Aeronautics, vol. 31, no. 11, pp. 2111-2123, 2018.

[35] R. Mahmood, S. Bilal, A. H. Majeed, I. Khan, and E.-S. M. Sherif, "A comparative analysis of flow features of Newtonian and power law material: a New configuration," Journal of Materials Research and Technology, vol. 12, 2019.
[36] W. S. Abbasi, S. U. Islam, and H. Rahman, "Proximity effects on characteristics of flow around three inline square cylinders," Mathematical Problems in Engineering, vol. 2019, Article ID 1752803, 14 pages, 2019.

[37] I. Khan, "Finite element least square technique for Newtonian fluid flow through a semicircular cylinder of recirculating region via COMSOL multiphysics," Jurnal Matematika, vol. 2020, Article ID 8869308, 11 pages, 2020.

[38] J. C. Tomio, M. M. Martins, M. Vaz, and P. S. B. Zdanski, “A numerical methodology for simulation of non-Newtonian viscoelastic flows," Numerical Heat Transfer Part B Fundam.vol. 78, no. 6, pp. 1-15, 2020.

[39] R. Mahmood, S. Bilal, A. H. Majeed, I. Khan, and K. S. Nisar, "CFD analysis for characterization of non-linear power law material in a channel driven cavity with a square cylinder by measuring variation in drag and lift forces," Journal of $M a$ terials Research and Technology, vol. 67, 2020.

[40] S. Bilal, R. Mahmood, A. H. Majeed, I. Khan, and K. S. Nisar, "Finite element method visualization about heat transfer analysis of Newtonian material in triangular cavity with square cylinder," Journal of Materials Research and Technology, vol. 9, no. 3, pp. 4904-4918, 2020.

[41] A. Mehmood, R. Mahmood, A. H. Majeed, and F. J. Awan, "Flow of the bingham-papanastasiou regularized material in channel in the presence of obstacles: correlation between hydrodynamic forces and spacing of obstacles," Modelling and Simulation in Engineering, vol. 2021, Article ID 5583110, 14 pages, 2021.

[42] M. Schaefer and S. Turek, "Benchmark computations of laminar flow around a cylinder," Notes on Numerical Fluid Mechanics, vol. 52, pp. 547-566, 1996. 